
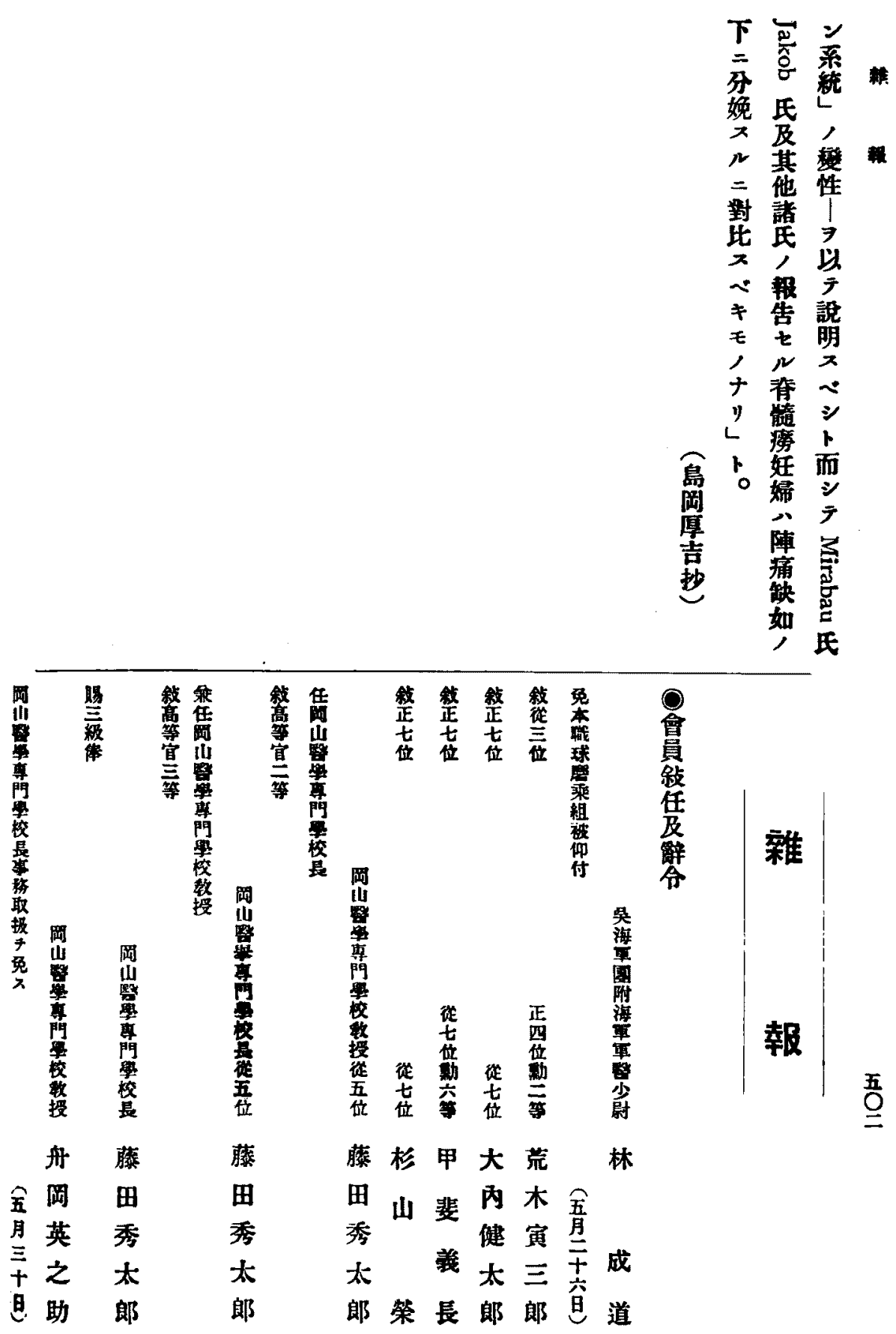


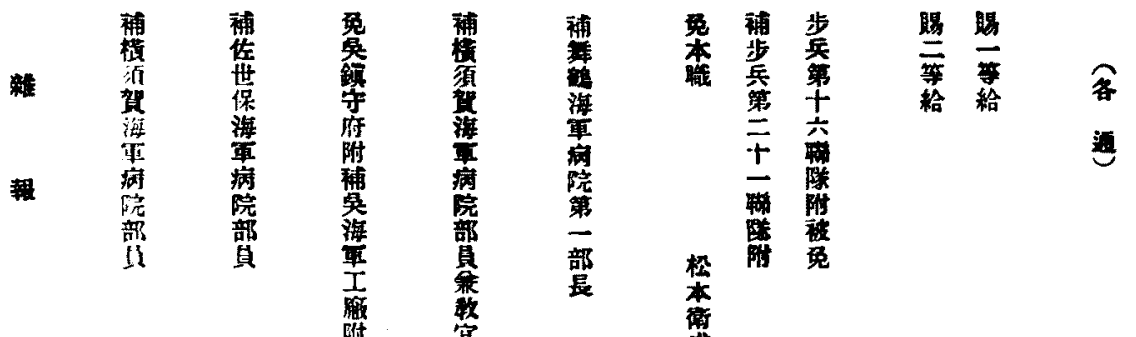

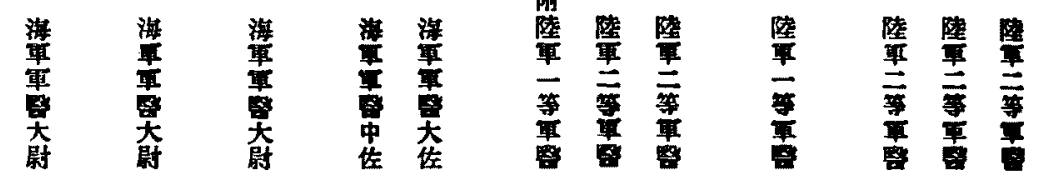

营藤 泉三服矢高高松中小上

今田田井部尽摆原原吾田村橋田

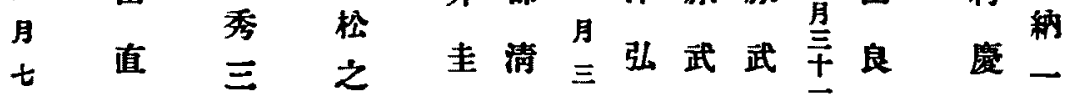

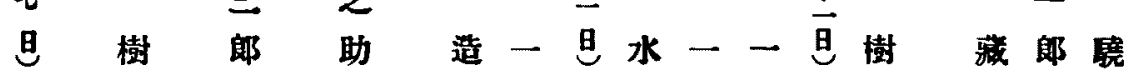

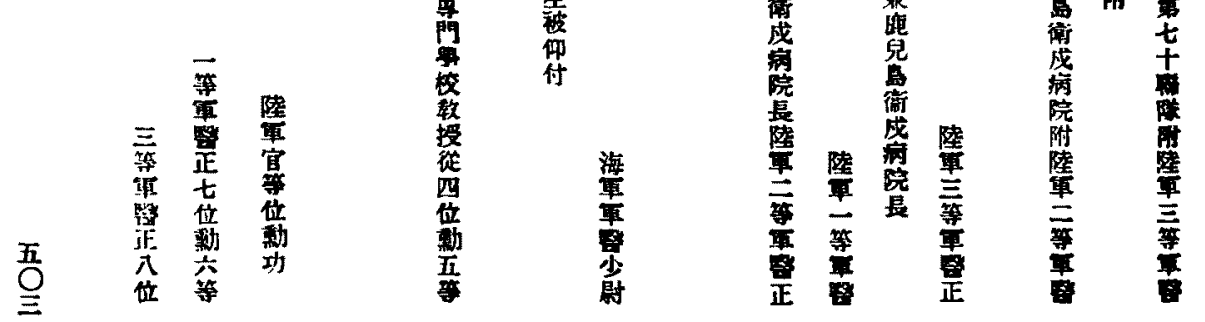

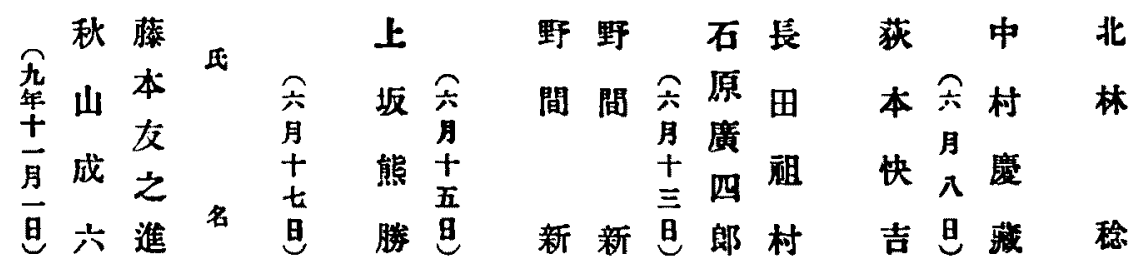



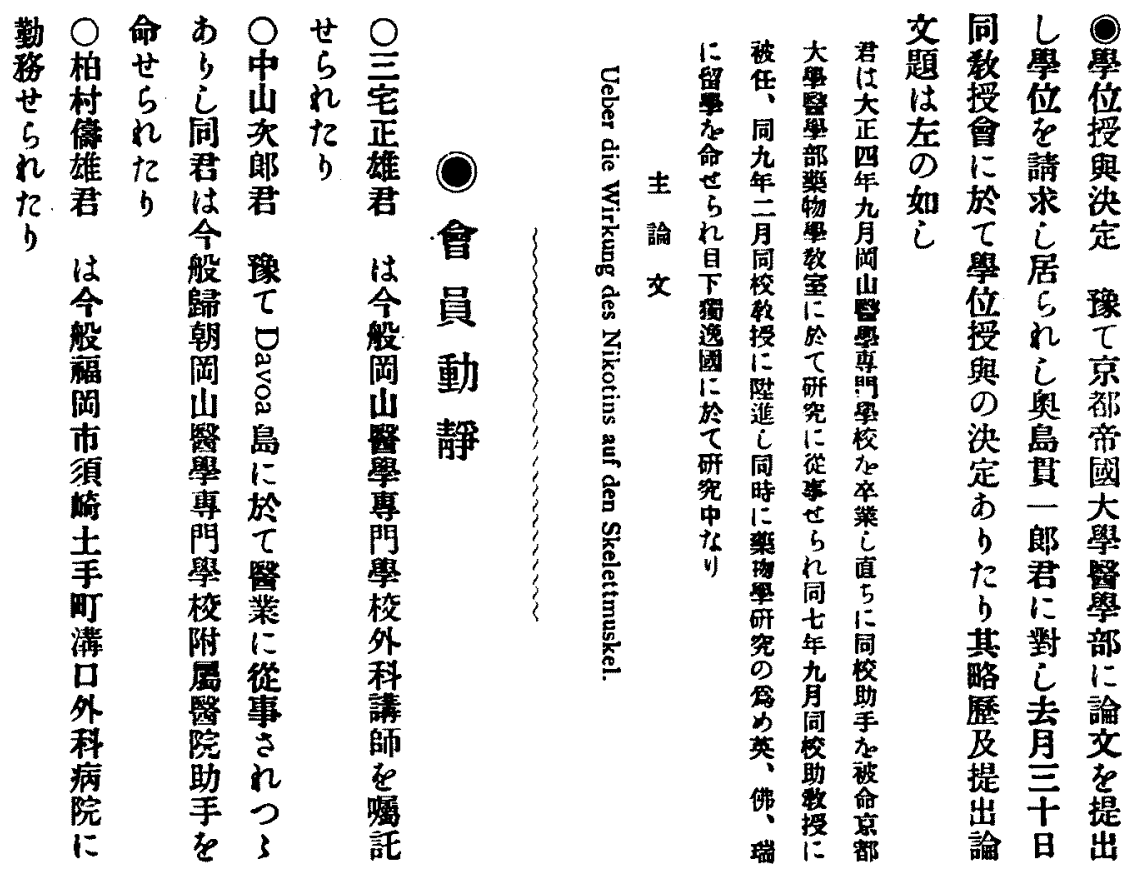

巳町校竹

泃に磨内

巨於卒恂

哀 $\tau$ 業造

悼 開 $匚$ 君

落虺逝

堪市了

人居駱

さ 5 徽 君

万れ院は

なしに明

b 加蔌 治

本枒声

四基宍

日後年

永湓阙

眠 山

せ解覺

证同

た市明

b 胡 學

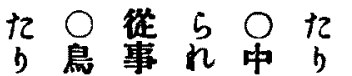
越

翰 5 村

夫肪吉

君机国君

は 支

䒜は

含般兵

兵 聯 粕

庫 和 相

樏

II

遥

郡

中

谷

村

に

轉

居

占
里生

安東

㴒 明

㗨 病

院 院

炛

統

營 勤

診㹩

㻮台

\section{㒕 泼}

